May, 2014

\title{
Comparison of reduction agents in the synthesis of infinite-layer $\mathrm{LaNiO}_{2}$ films
}

\author{
Ai Ikeda ${ }^{a, b}$, Takaaki Manabe ${ }^{c}$, and *Michio Naito ${ }^{a}$ \\ ${ }^{\mathrm{a}}$ Department of Applied Physics, Tokyo University of Agriculture and Technology \\ Naka-cho 2-24-16, Koganei, Tokyo 184-8588, Japan \\ ${ }^{b}$ Research Fellow of the Japan Society for the Promotion of Science \\ ${ }^{c}$ National Institute of Advanced Industrial Science and Technology (AIST) \\ Higashi 1-1-1, Tsukuba, Ibaraki 305-8565, Japan
}




\begin{abstract}
Reduction agents, such as an activated carbon, $\mathrm{TiH}_{2}$, and $\mathrm{CaH}_{2}$ powders, were compared from a viewpoint of the facility for the topotactic reduction of $\mathrm{LaNiO}_{3}$ to $\mathrm{LaNiO}_{2}$ films. The activated carbon did not yield infinite-layer $\mathrm{LaNiO}_{2}$ whereas both of $\mathrm{TiH}_{2}$ and $\mathrm{CaH}_{2}$ yielded infinite-layer $\mathrm{LaNiO}_{2}$ with low resistivity $(\sim 1 \mathrm{~m} \Omega \mathrm{cm}$ at $300 \mathrm{~K})$ as well as metallic behavior down to $70 \mathrm{~K}$. Thermal desorption spectroscopy indicated that $\mathrm{H}_{2}$ released from metal hydrides plays a dominant role in the topotactic reduction.
\end{abstract}

\title{
PACS: 74.10.+v, 74.62.Dh
}

Key words: infinite-layer structure, nickel oxide, topotactic reduction, metal hydride

*) Corresponding author. Address: Department of Applied Physics, Tokyo University of Agriculture and Technology, Naka-cho 2-24-16, Koganei, Tokyo 184-8588, Japan. Tel. +81 42388 7229; fax: +81 42385 6255. e-mail address: minaito@cc.tuat.ac.jp 


\section{Introduction}

In transition-metal oxides, octahedral or tetrahedral oxygen coordination is common as is found typically in perovskites and spinels whereas square-planar coordination is less common. The trend can be understood from the isotropic nature in ionic bonding of oxides. From the simple viewpoint of the crystal filed stabilization energy in ionically bonded structures, the square-planar geometry is stabilized by the Jahn-Teller effect, hence it may occur with $d^{9}$ and low-spin $d^{8}$ (possibly also low-spin $d^{7}$ ) ions [1]. Indeed this seems to be the case for the square-planar oxides formed with $\mathrm{Cu}^{2+}\left(3 d^{9}\right), \mathrm{Pd}^{2+}\left(4 d^{8}\right)$, and $\mathrm{Pt}^{2+}\left(5 d^{8}\right)$ ions [2]. $\mathrm{Ni}^{1+}$, which has the same $3 d^{9}$ electron configuration as $\mathrm{Cu}^{2+}$, may be another candidate to have square-planar coordination. In general, however, nickelates unlike cuprates prefer the octahedral coordination, so it had been believed for a long time that square-planar nickelates would not be stable. However, Crespin et al. achieved the synthesis of square-planar $\mathrm{LaNiO}_{2}$ in 1983 [3,4]. They synthesized highly metastable $\mathrm{LaNiO}_{2}$ by topotactic hydrogen reduction of perovskite $\mathrm{LaNiO}_{3}$ at low temperatures $\left(\sim 300^{\circ} \mathrm{C}\right)$. Here "topotaxy" means that the cation framework is reserved with oxygen atoms removed regularly (not randomly). $\mathrm{LaNiO}_{2}$ takes the so-called infinite-layer structure, which attracted much interest after the discovery of high- $T_{\mathrm{c}}$ cuprates because it is isostructural to $\mathrm{SrCuO}_{2}$, the parent compound of superconducting $\mathrm{Sr}_{0.9} \mathrm{La}_{0.1} \mathrm{CuO}_{2}$ with $T_{\mathrm{c}}=44 \mathrm{~K}$.

After the first synthesis of $\mathrm{LaNiO}_{2}$, there were some struggles by other groups to reproduce the experiments by Crespin et al. by means of hydrogen reduction, which may be attributed partly to insufficient purity of hydrogen. In 1999, however, Hayward et al. succeeded in isolating $\mathrm{LaNiO}_{2}$ using $\mathrm{NaH}$, one of the most powerful reducing agents [5]. Later, other groups have employed a more convenient hydride, 
$\mathrm{CaH}_{2}$, for the synthesis of infinite-layer $\mathrm{LaNiO}_{2}[6,7]$. In our previous articles, we have demonstrated that the thin-film synthesis of $\mathrm{LaNiO}_{2}$ is rather easy as compared with the bulk synthesis, thanks to a large-surface-to-volume ratio. Our extensive optimizations for synthesis (metal organic decomposition) and subsequent hydrogen reduction conditions have produced conducting $\mathrm{LaNiO}_{2}$ films with resistivity lower than $1 \mathrm{~m} \Omega \mathrm{cm}$ at $300 \mathrm{~K}$ [8]. In this article, we report a further improvement in conductivity of $\mathrm{LaNiO}_{2}$, which is achieved employing metal hydrides as a reducing agent such as $\mathrm{TiH}_{2}$ and $\mathrm{CaH}_{2}$. The films show metallic resistivity down to $70 \mathrm{~K}$ and a weak upturn at lower temperatures.

\section{Experimental}

Starting $\mathrm{LaNiO}_{3}$ films were prepared by metal organic decomposition (MOD) using $\mathrm{La}$ and $\mathrm{Ni}$ 2-ethylhexanoate solutions. The stoichiometric mixture of 2-ethylhexanoate solutions was spin-coated on (110) $\mathrm{NdGaO}_{3}$ (NGO) substrates. The films were first calcined at $500^{\circ} \mathrm{C}$ in air to obtain precursors, next fired at $900^{\circ} \mathrm{C}$ in a tubular furnace under oxygen $\left(p_{\mathrm{O} 2}=1 \mathrm{~atm}\right)$, and then furnace-cooled in pure oxygen down to $300^{\circ} \mathrm{C}$. Subsequently the films were given topotactic reduction with various reducing agents such as activated carbon, $\mathrm{TiH}_{2}$, and $\mathrm{CaH}_{2}$. In the reduction, an as-grown $\mathrm{LaNiO}_{3}$ film was embedded in the powder of the agent in a quartz tube, and then the tube was evacuated $\left(\leq 10^{-6}\right.$ Torr $)$ and sealed. The sealed tube was heated in a tubular furnace or by a mantle heater. The process parameters in reduction are the temperature $\left(T_{\text {red }}\right)$ and time $\left(t_{\text {red }}\right)$. Thermal desorption spectroscopy of $\mathrm{H}_{2}$ from metal hydrides (without films) was performed using a quadrupole mass spectrometer (Stanford Research Systems, RGA100). 
After reduction, the film surface was washed with 2-butanol to remove byproducts and unreacted reducing agents. The film thickness was typically $800 \AA$ although it may vary film by film to some extent. Films with no reduction are referred to "as-grown" in this article. The crystal structure and lattice parameters of the films

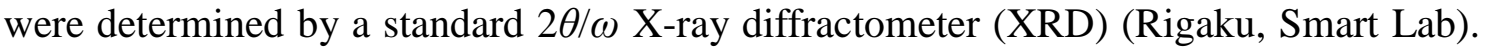
The resistivity was measured by a standard four -probe method.

\section{Results and discussion}

\section{1. Reduction using activated carbon powder}

We first present the results using activated carbon powder as a reducing agent. An as-grown $\mathrm{LaNiO}_{3}$ film was embedded typically in a $\sim 0.2 \mathrm{~g}$ amount of activated carbon powder and heated in vacuum at $T_{\text {red }}=500-700^{\circ} \mathrm{C}$ for $t_{\text {red }}$ of $30 \mathrm{~min}$. No change in films was observed at $T_{\text {red }} \leq 500^{\circ} \mathrm{C}$. The films were converted partly to brownmillerite $\mathrm{La}_{2} \mathrm{Ni}_{2} \mathrm{O}_{5}$ by reduction at $600^{\circ} \mathrm{C}$, and decomposed completely to $\mathrm{La}_{2} \mathrm{NiO}_{4}$ at $700^{\circ} \mathrm{C}$. Infinite-layer $\mathrm{LaNiO}_{2}$ is not formed at any $T_{\text {red. }}$ The standard reaction enthalpy $\left(\Delta H^{\circ}\right)$ for $\mathrm{C}(\mathrm{s})+\mathrm{O}_{2}(\mathrm{~g}) \rightarrow \mathrm{CO}_{2}(\mathrm{~g})$ is $-393.5 \mathrm{~kJ} / \mathrm{mol}$, which is smaller in magnitude than $-483.6 \mathrm{~kJ} / \mathrm{mol}$ for $2 \mathrm{H}_{2}(\mathrm{~g})+\mathrm{O}_{2}(\mathrm{~g}) \rightarrow 2 \mathrm{H}_{2} \mathrm{O}(\mathrm{g})$ [9]. But this may not be a reason for the unsuccessful result. The true reason may be that reduction of $\mathrm{LaNiO}_{3}$ films with carbon powder proceeds via solid-solid reaction, which requires higher temperatures than reduction via solid-gas reaction. In fact, the topotactic reduction of $\mathrm{LaNiO}_{3}$ films to $\mathrm{LaNiO}_{2}$ in hydrogen gas is completed at $380-420^{\circ} \mathrm{C}$ for 10 min, and the decomposition to $\mathrm{La}_{2} \mathrm{NiO}_{4}$ starts at $T_{\text {red }} \geq 450^{\circ} \mathrm{C}$, indicating that the reduction proceeds at substantially lower temperatures than in reduction with carbon. The solid-state reaction route appears not to be favorable for stabilizing infinite-layer 
$\mathrm{LaNiO}_{2}$.

\section{2. Thermal desorption spectroscopy for $\mathrm{TiH}_{2}$ and $\mathrm{CaH}_{2}$}

So far $\mathrm{NaH}$ and $\mathrm{CaH}_{2}$ have been employed as a reducing agent for the topotactic reduction from $\mathrm{LaNiO}_{3}$ to $\mathrm{LaNiO}_{2}$. But $\mathrm{TiH}_{2}$ has not been attempted previously as far as we know. There is some controversy regarding how the reduction of oxides proceeds with hydrides, namely via solid-solid (oxide-hydride) reaction or via $\mathrm{H}_{2}$ gas released from hydrides. The first report by Hayward et al. supported the solid-solid reaction since intimate grinding of $\mathrm{LaNiO}_{3}$ and $\mathrm{NaH}$ powders is inevitable for the successful synthesis of $\mathrm{LaNiO}_{2}$. In contrast, the recent report by Kobayashi et al. supported the reaction via $\mathrm{H}_{2}$ gas from the following experimental observations [10]. Employing films of $\mathrm{LaNiO}_{3}$ instead of powder, they performed reduction with a film and $\mathrm{CaH}_{2}$ either physically contacted or separated, and compared the results. $\mathrm{LaNiO}_{2}$ was obtained even in separated reduction at the same temperature $\left(280^{\circ} \mathrm{C}\right)$ as in contacted reduction, but with a longer time required. This is strong evidence that the reduction proceeds via gas phase intermediates, most likely $\mathrm{H}_{2}$ gas. In order to evaluate the partial pressure of $\mathrm{H}_{2}$ gas released from metal hydrides in reduction, we performed thermal desorption spectroscopy. Figure 1 shows the results. It plots the partial hydrogen pressure $\left(p_{\mathrm{H} 2}\right)$ released from $\mathrm{CaH}_{2}$ and $\mathrm{TiH}_{2}$ as a function of temperature on ramping up the temperature by $1.6^{\circ} \mathrm{C} / \mathrm{min}$. For $\mathrm{TiH}_{2}, p_{\mathrm{H} 2}$ starts to rise at $\sim 150^{\circ} \mathrm{C}$, and monotonically increases with temperature. After a rapid increase at $380 \sim 400^{\circ} \mathrm{C}, p_{\mathrm{H} 2}$ becomes nearly constant upon a further increase of temperature. The reaction for releasing $\mathrm{H}_{2}$ gas from $\mathrm{TiH}_{2}$ appears to be simply $\mathrm{TiH}_{2} \rightarrow \mathrm{Ti}(\mathrm{s})+\mathrm{H}_{2}(\mathrm{~g})$. In contrast, for $\mathrm{CaH}_{2}, p_{\mathrm{H} 2}$ shows strange behavior. Namely, $p_{\mathrm{H} 2}$ is already high at ambient 
temperature, and the $p_{\mathrm{H} 2}-T$ curve is shifted to lower temperatures by $120-150^{\circ} \mathrm{C}$ as compared with the $p_{\mathrm{H} 2}-T$ curve for $\mathrm{TiH}_{2}$ up to $250^{\circ} \mathrm{C}$. The $p_{\mathrm{H} 2}-T$ of $\mathrm{CaH}_{2}$ flattens above $250^{\circ} \mathrm{C}$ and drops by one order of magnitude with some wiggles above $300^{\circ} \mathrm{C}$. The irregular behavior observed seems to indicate that the reaction to release $\mathrm{H}_{2}$ in $\mathrm{CaH}_{2}$ may not be simply $\mathrm{CaH}_{2} \rightarrow \mathrm{Ca}(\mathrm{s})+\mathrm{H}_{2}(\mathrm{~g})$. This speculation is also supported from the rather high dissociation temperature $\left(885^{\circ} \mathrm{C}\right)$ reported for $\mathrm{CaH}_{2}$ [11]. Kobayashi et al. pointed out the same issue [10]. According to their estimate, the equilibrium constant for $\mathrm{CaH}_{2} \rightarrow \mathrm{Ca}(\mathrm{s})+\mathrm{H}_{2}(\mathrm{~g})$ is only $10^{-8}$ even at $400^{\circ} \mathrm{C}$. The value makes it difficult to explain the observed high $p_{\mathrm{H} 2}$ at temperatures below $400^{\circ} \mathrm{C}$. Instead of the simple dissociation, Kobayashi et al. proposed the reaction between the hydride and hydroxide, namely $\mathrm{CaH}_{2}+\mathrm{Ca}(\mathrm{OH})_{2} \rightarrow 2 \mathrm{CaO}(\mathrm{s})+2 \mathrm{H}_{2}(\mathrm{~g})$. The equilibrium constant of this reaction is estimated to be high $\left(10^{12}\right.$ at $\left.400^{\circ} \mathrm{C}\right) . \quad \mathrm{Ca}(\mathrm{OH})_{2}$ is always present in $\mathrm{CaH}_{2}$ powder as impurity, which is produced by the reaction between $\mathrm{CaH}_{2}$ and atmospheric moisture. This reaction may explain the observed irregular $p_{\mathrm{H} 2}-T$ curve [12].

\section{3. Reduction using $\mathrm{TiH}_{2}$}

We next present the experimental results of reduction using $\mathrm{TiH}_{2}$. The films were reduced at different $T_{\text {red }}\left(250-400^{\circ} \mathrm{C}\right)$ with a fixed $t_{\text {red }}$ of $120 \mathrm{~min}$. In reduction using $\mathrm{TiH}_{2}$, the amount of $\mathrm{TiH}_{2}$ is also one important parameter, so it was varied from $\sim 0.5 \mathrm{~g}$ to $\sim 25 \mathrm{~g}$. With $0.5 \mathrm{~g}$ of $\mathrm{TiH}_{2}$, the reduction at $T_{\text {red }}=350^{\circ} \mathrm{C}$ yielded films of a mixture of $\mathrm{La}_{2} \mathrm{Ni}_{2} \mathrm{O}_{5}$ and $\mathrm{LaNiO}_{2}$ whereas the reduction at $T_{\text {red }}=375^{\circ} \mathrm{C}$ yielded films of single-phase $\mathrm{LaNiO}_{2}$. The reduction at $T_{\text {red }} \geq 400^{\circ} \mathrm{C}$ decomposed the infinite-layer phase completely and yielded films of $\mathrm{La}_{2} \mathrm{NiO}_{4}$. The range of $T_{\text {red }}$ for single-phase 
$\mathrm{LaNiO}_{2}$ films to form is very narrow and it is close to the temperature range (350-400 ${ }^{\circ} \mathrm{C}$ ) in which $p_{\mathrm{H} 2}$ from $\mathrm{TiH}_{2}$ rapidly increases as shown in Fig. 1. The optimum $T_{\text {red }}$ varies with the amount of $\mathrm{TiH}_{2}$ in reduction. Figure 2 summarizes the (002) peak intensity and the $c_{0}$ of infinite-layer $\mathrm{LaNiO}_{2}$ as a function of $T_{\text {red. }}$. As the amount of $\mathrm{TiH}_{2}$ increases, the optimum $T_{\text {red }}$ becomes lower $\left(T_{\text {red }}=375^{\circ} \mathrm{C}\right.$ for $0.5 \mathrm{~g}$, $320^{\circ} \mathrm{C}$ for $5 \mathrm{~g}$, and $288^{\circ} \mathrm{C}$ for $25 \mathrm{~g}$ ), and simultaneously the (002) peak intensity of the films reduced at optimum $T_{\text {red }}$ becomes stronger. As seen in Fig. 2(b), our $c_{0}$ values of the films reduced using $\mathrm{TiH}_{2}$ is in a fair agreement with the $c_{0}$ of bulk samples. The $c_{0}$ values decreases slightly with $T_{\text {red }}$ as a global trend on comparing several $\mathrm{LaNiO}_{2}$ films reduced with a different amount of $\mathrm{TiH}_{2}$.

Figure 3 shows the temperature dependence of resistivity $(\rho-T)$ for the $\mathrm{LaNiO}_{2}$ films prepared with a different amount of $\mathrm{TiH}_{2}$. The films were reduced so as to minimize the resistivity. The $T_{\text {red }}$ is $375^{\circ} \mathrm{C}$ for $0.5 \mathrm{~g}, 325^{\circ} \mathrm{C}$ for $5 \mathrm{~g}$, and $300^{\circ} \mathrm{C}$ for $25 \mathrm{~g}$, respectively, which is almost the same as or slightly $\left(5-10^{\circ} \mathrm{C}\right)$ higher than the $T_{\text {red }}$ giving the strongest XRD peaks. All the films in Fig. 3 are metallic down to $70-110 \mathrm{~K}$ but with a resistivity upturn at lower temperatures. The $\rho(300 \mathrm{~K})$ is $\sim 1 \mathrm{~m} \Omega \mathrm{cm}$ for the films reduced with $5 \mathrm{~g}$ and $25 \mathrm{~g}$ of $\mathrm{TiH}_{2}$ whereas it is $\sim 3.4 \mathrm{~m} \Omega \mathrm{cm}$ for the film reduced with $0.5 \mathrm{~g}$ of $\mathrm{TiH}_{2}$. Summarizing the results with $\mathrm{TiH}_{2}$, a larger amount $(\geq 5 \mathrm{~g})$ of $\mathrm{TiH}_{2}$ lowers the reduction temperature, and yields $\mathrm{LaNiO}_{2}$ films with better crystallinity and lower resistivity.

\section{4. Reduction using $\mathrm{CaH}_{2}$}

In reduction using $\mathrm{CaH}_{2}$, the amount of $\mathrm{CaH}_{2}$ is fixed $(\sim 0.5 \mathrm{~g})$ since a larger amount of $\mathrm{CaH}_{2}$ made the results worse. The $T_{\text {red }}$ was varied from 275 to $400^{\circ} \mathrm{C}$ and 
the $t_{\text {red }}$ was fixed at $120 \mathrm{~min}$. The reduction at $T_{\text {red }}=275^{\circ} \mathrm{C}$ yielded films of a mixture of starting $\mathrm{LaNiO}_{3}, \mathrm{La}_{2} \mathrm{Ni}_{2} \mathrm{O}_{5}$, and $\mathrm{LaNiO}_{2}$ whereas the reduction at $T_{\text {red }}=300-375^{\circ} \mathrm{C}$ yielded single-phase $\mathrm{LaNiO}_{2}$ films. The reduction at $T_{\text {red }} \geq 400^{\circ} \mathrm{C}$ decomposed the infinite-layer phase and yielded films of $\mathrm{La}_{2} \mathrm{NiO}_{4}$. The (002) peak intensity and the $c_{0}$ of infinite-layer $\mathrm{LaNiO}_{2}$ as a function of $T_{\text {red }}$ is summarized in Fig. 2. As seen in Fig. 2(a), the range of $T_{\text {red }}$ for single-phase $\mathrm{LaNiO}_{2}$ to form in $\mathrm{CaH}_{2}$ reduction is wide and covers the ranges of $T_{\text {red }}$ for single-phase $\mathrm{LaNiO}_{2}$ to form in the reduction with $0.5,5$, and $25 \mathrm{~g}$ of $\mathrm{TiH}_{2}$. As shown in Fig. 2, the XRD peaks intensity grows with lowering $T_{\text {red. }}$ This trend is also seen in $\mathrm{TiH}_{2}$ reduction if one compares the peak intensities for a different amount of $\mathrm{TiH}_{2}$. Figure 4 shows the $\rho$-T curves for the $\mathrm{LaNiO}_{2}$ films reduced with $\mathrm{CaH}_{2}$ at different $T_{\text {red }}\left(300-375^{\circ} \mathrm{C}\right)$. The films reduced at $T_{\text {red }}=300^{\circ} \mathrm{C}$ and $325^{\circ} \mathrm{C}$ show $\rho(300 \mathrm{~K})$ as low as $\sim 1 \mathrm{~m} \Omega \mathrm{cm}$ and a metallic temperature dependence down to 70 $\mathrm{K}$ but with an upturn at lower temperatures. Increasing $T_{\text {red, }}$, the $\rho(300 \mathrm{~K})$ and also the resistivity minimum temperature $\left(T_{\min }\right)$ become higher. The trend in Fig. 4 resembles the trend seen in the $\rho-T$ (Fig. 3) of the films reduced with the different amount of $\mathrm{TiH}_{2}$. This implies that the trend in Fig. 3 may also be due to the increase of $T_{\text {red }}$ accompanied with a reduced amount of $\mathrm{TiH}_{2}$ in reduction.

\subsection{Comparison of $\mathrm{TiH}_{2}, \mathrm{CaH}_{2}$, and $\mathrm{H}_{2}$ reduction}

Next we compare the properties of $\mathrm{LaNiO}_{2}$ films prepared by different reduction agents. Figure 5 is a summary of the results for our best $\mathrm{LaNiO}_{2}$ films prepared with $\mathrm{TiH}_{2}$ and $\mathrm{CaH}_{2}$ :: (a) XRD and (b) $\rho$-T. For comparison, the data for films reduced with flowing hydrogen gas $\left(p_{\mathrm{H} 2}=1\right.$ atm) are also included. For each reduction agent, the reduction conditions are optimized. In Fig. 5(a), the $c_{0}$ of the 
$\mathrm{LaNiO}_{2}$ films are also included. The values hardly depend on the reduction agents. The difference by reduction agents is observed most prominently in the resistivity. The $\mathrm{LaNiO}_{2}$ films prepared by either $\mathrm{TiH}_{2}$ or $\mathrm{CaH}_{2}$ reduction show lower $\rho(300 \mathrm{~K})$ and lower $T_{\min }$ than the films prepared by $\mathrm{H}_{2}$ reduction. The $T_{\min }$ is $70 \mathrm{~K}$ in metal-hydride reduction whereas it is $260 \mathrm{~K}$ in hydrogen reduction. One may think that the difference arises from the difference in the reduction process. For example, direct solid-solid (oxide-hydride) reaction may play an important role in metal-hydride reduction. But we argue against this possibility from the following reasons. Firstly, the infinite-layer phase did not form when we heated up a film embedded in metal-hydride powder in dynamic vacuum, namely we kept pumping a quartz tube left unsealed by a diffusion pump (base pressure of $\sim 10^{-6}$ Torr) during $\mathrm{TiH}_{2} / \mathrm{CaH}_{2}$ reduction. In dynamic vacuum, $\mathrm{H}_{2}$ gas released from metal hydrides is pumped out and the reduction route via gas-solid reaction is cut off. The experimental results strongly supports that the gas phase is prerequisite for the formation of $\mathrm{LaNiO}_{2}$. Secondly there is not much difference in the $T_{\text {red }}$ between $\mathrm{TiH}_{2} / \mathrm{CaH}_{2}$ and $\mathrm{H}_{2}$ reduction, as can be seen in the summary in Table I.

We speculate the reason for the difference in the resistivity of the films prepared by $\mathrm{TiH}_{2} / \mathrm{CaH}_{2}$ and $\mathrm{H}_{2}$ reduction as follows. As shown in fig. 5(a), all the films are infinite-layer single-phase but a mixture of $a$ - and $c$-axis oriented grains. The (200) peak of $a$-axis grains is smaller in the films reduced by metal hydrides than in the films reduced by flowing hydrogen gas, although the reason is yet to be understood. The smaller amount of $a$-axis oriented grains is favorable for conductivity if one assumes that the electron transport takes place in the two-dimensional $\mathrm{NiO}_{2}$ planes. As another reason, the hydrogen gas we used for reduction was not of an ultra-pure 
semiconductor grade but of a standard grade, and may contain $\mathrm{O}_{2}, \mathrm{H}_{2} \mathrm{O}, \mathrm{CO}_{2}$, etc. as impurities. Therefore the environment during reduction may be cleaner in metal-hydride reduction than in hydrogen reduction. This may be a possible reason why short $t_{\text {red }}(\sim 10 \mathrm{~min})$ is favorable in hydrogen reduction whereas long $t_{\text {red }}(2-12 \mathrm{hr})$ is favorable in metal hydride reduction.

\section{Summary}

In summary, activated carbon, $\mathrm{CaH}_{2}$, and $\mathrm{TiH}_{2}$ were examined from a viewpoint of the suitability for topotactic reduction to isolate infinite-layer $\mathrm{LaNiO}_{2}$ from $\mathrm{LaNiO}_{3}$ films. In meta-hydride reduction, the gas-solid reduction proceeds with hydrogen released from the thermal decomposition of $\mathrm{TiH}_{2}$ or from the reaction between $\mathrm{CaH}_{2}$ and $\mathrm{Ca}(\mathrm{OH})_{2}$, which is effective to isolate $\mathrm{LaNiO}_{2}$ at low temperatures. The low resistivity with $\rho(300 \mathrm{~K}) \sim 1 \mathrm{~m} \Omega \mathrm{cm}$ as well as the metallic resistivity down to $70 \mathrm{~K}$ are observed in the $\mathrm{LaNiO}_{2}$ films prepared with either $\mathrm{TiH}_{2}$ or $\mathrm{CaH}_{2}$. By contrast, no $\mathrm{LaNiO}_{2}$ film has been obtained with an activated carbon. This implies that the solid-state reduction is not favorable for low-temperature reduction.

\section{Acknowledgements}

The work was partly supported by KAKENHI B (23340098) from Japan Society for the Promotion of Science (JSPS) and also by Advanced Low Carbon Technology (ALCA), Japan Science and Technology Agency. 


\section{References}

[1] P. A. Cox, Transition Metal Oxides (Oxford University Press, Oxford, U.K., (1992)), Chap. 2, p. 37-47.

[2] Recently an example against the Jahn-Teller scenario was demonstrated by $\mathrm{SrFeO}_{2}$, a square-planar oxide formed with a non-Jahn-Teller $\mathrm{Fe}^{2+}\left(3 d^{6}\right)$ ion. This compound is a metastable phase synthesized by topotactic reduction using $\mathrm{CaH}_{2}$ as a reduction agent. It is claimed that the square-planar geometry is stabilized by strong covalency that favors directional Fe-O bonding in this compound. See Y. Tsujimoto, C. Tassel, N. Hayashi, T. Watanabe, H. Kageyama, K. Yoshimura, M. Takano, M. Ceretti, C. Ritter, and W. Paulus, Nature 450 (2007) 1062.

[3] M. Crespin, P. Levitz, and L. Gatineau, J. Chem. Soc. Faraday Trans. 2 (79) (1983) 1181.

[4] P. Levitz, M. Crespin, and L. Gatineau, J. Chem. Soc. Faraday Trans. 2 (79) (1983) 1195.

[5] M. A. Hayward, M. A. Green, M. J. Rosseinsky, and J. Sloan, J. Am. Chem. Soc. 121 (1999) 8843.

[6] M. Kawai, S. Inoue, M. Mizumaki, N. Kawamura, N. Ichikawa, and Y. Shimakawa, Appl. Phys. Lett. 94 (2009) 082102.

[7] T. Takamatsu, M. Kato, T. Noji, and Y. Koike, Jpn. J. Appl. Phys. 49 (2010) 093101.

[8] A. Ikeda, T. Manabe, and M. Naito, Physica C 495 (2013) 134.

[9] P. W. Atkins, Physical Chemistry, $4^{\text {th }}$ ed. (Oxford University Press, Oxford, U.K., (1990)), Chap. 2. 
[10] Y. Kobayashi, Z. Li, K. Hirai, C. Tassel, F. Loyer, N. Ichikawa, N. Abe, T. Yamamoto, Y. Shimakawa, K. Yoshimura, M. Takano, O. J. Hernandez, and H. Kageyama, J. Solid State Chem. 207 (2013) 190.

[11] N. N. Greenwood and A. Earnshaw, A Chemistry of the Elements, $2^{\text {nd }}$ ed. (Butterworth-Heinemann, Oxford, U.K., (1997)), p 66.

[12] $\mathrm{CaH}_{2}$ used in this work is a product of Wako Inc., and its purity is $80 \%$. 
Table I. Summary of the optimal reduction temperature $T_{\text {red }}$ with a fixed $t_{\text {red }}$ for various reduction agents.

\begin{tabular}{|c|c|c|c|c|}
\hline \multirow{2}{*}{$\begin{array}{c}\text { Reduction } \\
\text { agents }\end{array}$} & \multirow{2}{*}{ amount } & \multicolumn{3}{|c|}{ Reduction time $\left(t_{\text {red }}\right)$} \\
\cline { 3 - 5 } & & $10 \mathrm{~min}$ & $2 \mathrm{~h}$ & $12 \mathrm{~h}$ \\
\hline $\mathrm{CaH}_{2}$ & $0.5 \mathrm{~g}$ & $375^{\circ} \mathrm{C}$ & $300^{\circ} \mathrm{C}$ & $275^{\circ} \mathrm{C}$ \\
\hline \multirow{3}{*}{$\mathrm{TiH}_{2}$} & $0.5 \mathrm{~g}$ & $425^{\circ} \mathrm{C}$ & $375^{\circ} \mathrm{C}$ & $325^{\circ} \mathrm{C}$ \\
\cline { 2 - 5 } & $5 \mathrm{~g}$ & & $325^{\circ} \mathrm{C}$ & \\
\cline { 2 - 5 } & $25 \mathrm{~g}$ & & $300^{\circ} \mathrm{C}$ & \\
\hline $\mathrm{H}_{2}$ & $1 \mathrm{~atm}$ & $380^{\circ} \mathrm{C}$ & $360^{\circ} \mathrm{C} *$ & \\
\hline
\end{tabular}

*This value of $T_{\text {red }}$ in $\mathrm{H}_{2}$ reduction is not for $t_{\text {red }}$ of $2 \mathrm{~h}$ but of $1.5 \mathrm{~h}$. 
Figure caption

Figure 1. Partial hydrogen pressures $\left(p_{\mathrm{H} 2}\right)$ taken for $0.5 \mathrm{~g}$ of $\mathrm{TiH}_{2}$ and $\mathrm{CaH}_{2}$ of on ramping up the temperature to $450^{\circ} \mathrm{C}$ by $1.6^{\circ} \mathrm{C} / \mathrm{min}$ in vacuum $\left(\sim 10^{-6} \mathrm{Torr}\right)$.

Figure 2. (a) The (002) peak intensity and (b) $c$-axis length of $\mathrm{LaNiO}_{2}$ films prepared with $\mathrm{CaH}_{2}$ and $\mathrm{TiH}_{2}$ as a function of $T_{\text {red, }}$, respectively. In fig. 2(b), the $c_{0}$ of bulk samples is also included by the thick bar, where $c_{0}=3.376 \AA$ for hydrogen reduced samples [3] and $c_{0}=3.375 \AA$ for $\mathrm{NaH}$ reduced samples [5].

Figure 3. The temperature dependence of resistivity $\rho$ - $T$ for $\mathrm{LaNiO}_{2}$ films reduced with a different amount of $\mathrm{TiH}_{2}(0.5-25 \mathrm{~g})$.

Figure 4. $\rho$-T characteristics of $\mathrm{LaNiO}_{2}$ films reduced with $\mathrm{CaH}_{2}$ at various $T_{\text {red }}$ $\left(300-375^{\circ} \mathrm{C}\right)$.

Figure 5. Structural and transport data for $\mathrm{LaNiO}_{2}$ films prepared with various reduction agents after optimizing reduction conditions: (a) XRD patterns and (b) $\rho-T$. For comparison, the data for films reduced in hydrogen is also included. The reduction conditions of these films are as follows: $T_{\text {red }}=325^{\circ} \mathrm{C}$ and $t_{\text {red }}=2 \mathrm{~h}$ in reduction with $\mathrm{TiH}_{2}(5 \mathrm{~g}), T_{\text {red }}=300^{\circ} \mathrm{C}$ and $t_{\text {red }}=2 \mathrm{~h}$ in reduction with $\mathrm{CaH}_{2}(0.5 \mathrm{~g})$, , $T_{\text {red }}=380^{\circ} \mathrm{C}$ and $t_{\text {red }}=10 \mathrm{~min}$ in hydrogen reduction $\left(p_{\mathrm{H} 2}=1 \mathrm{~atm}\right)$. 
Fig. 1

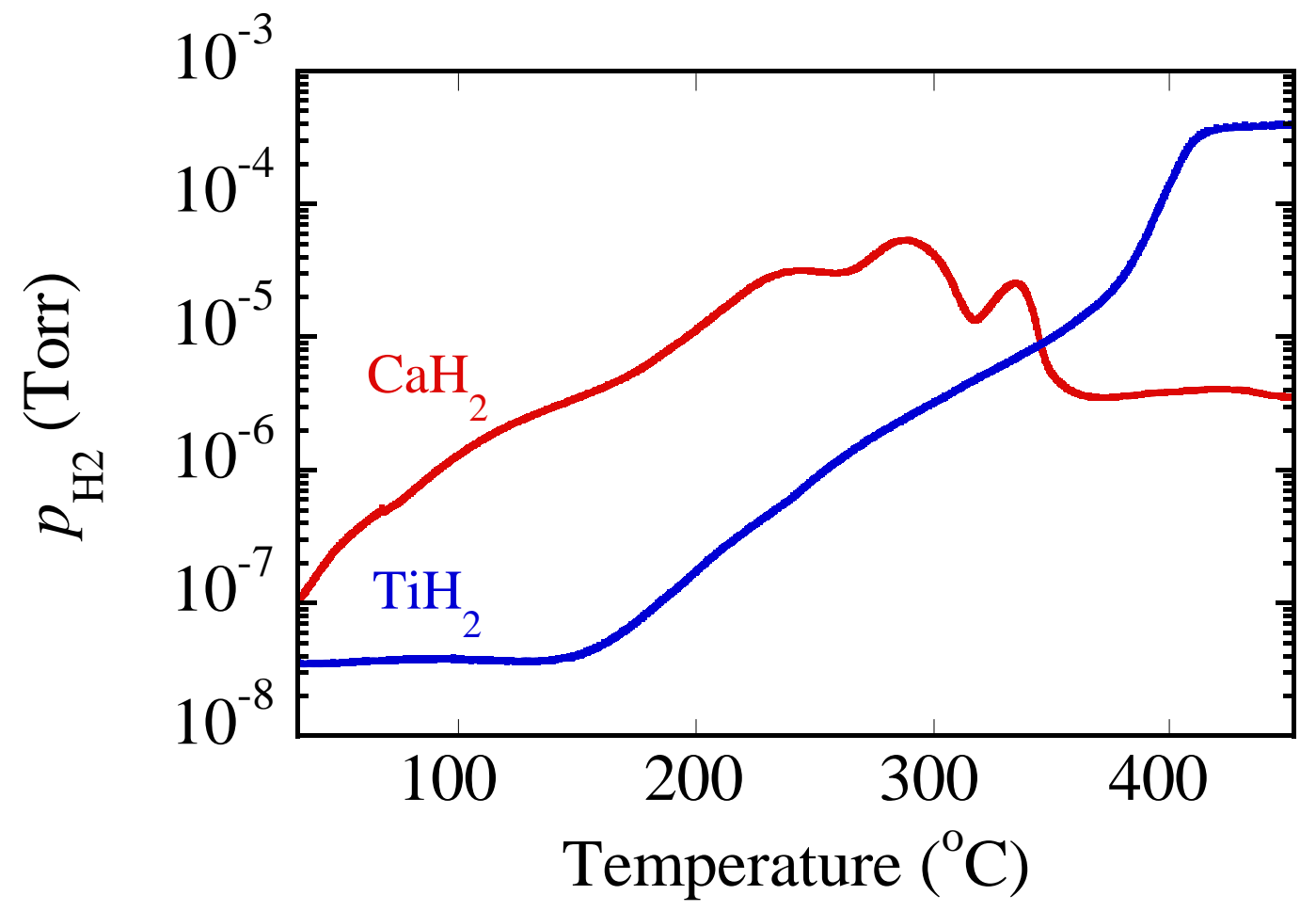


Fig. 2
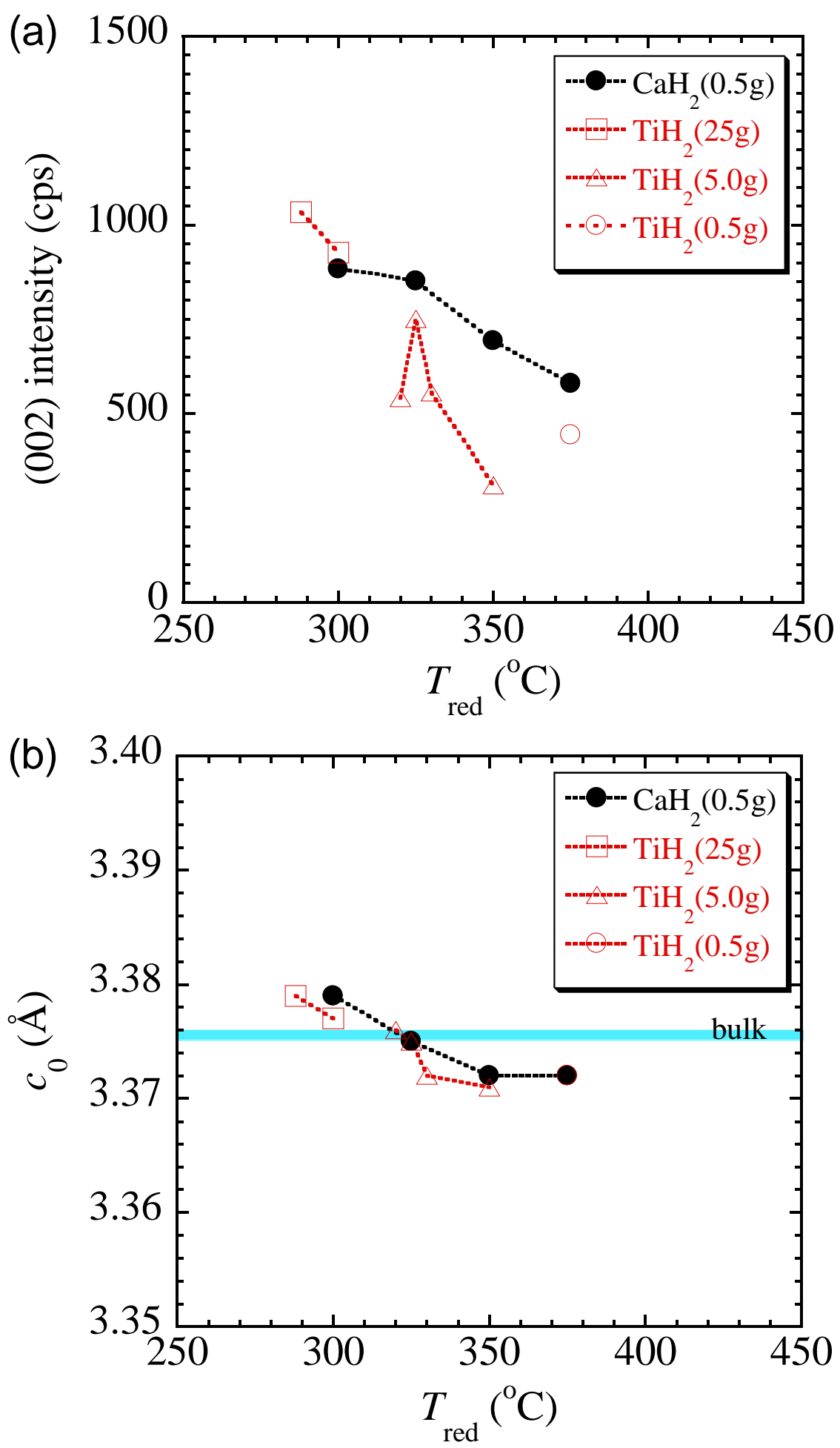
Fig. 3

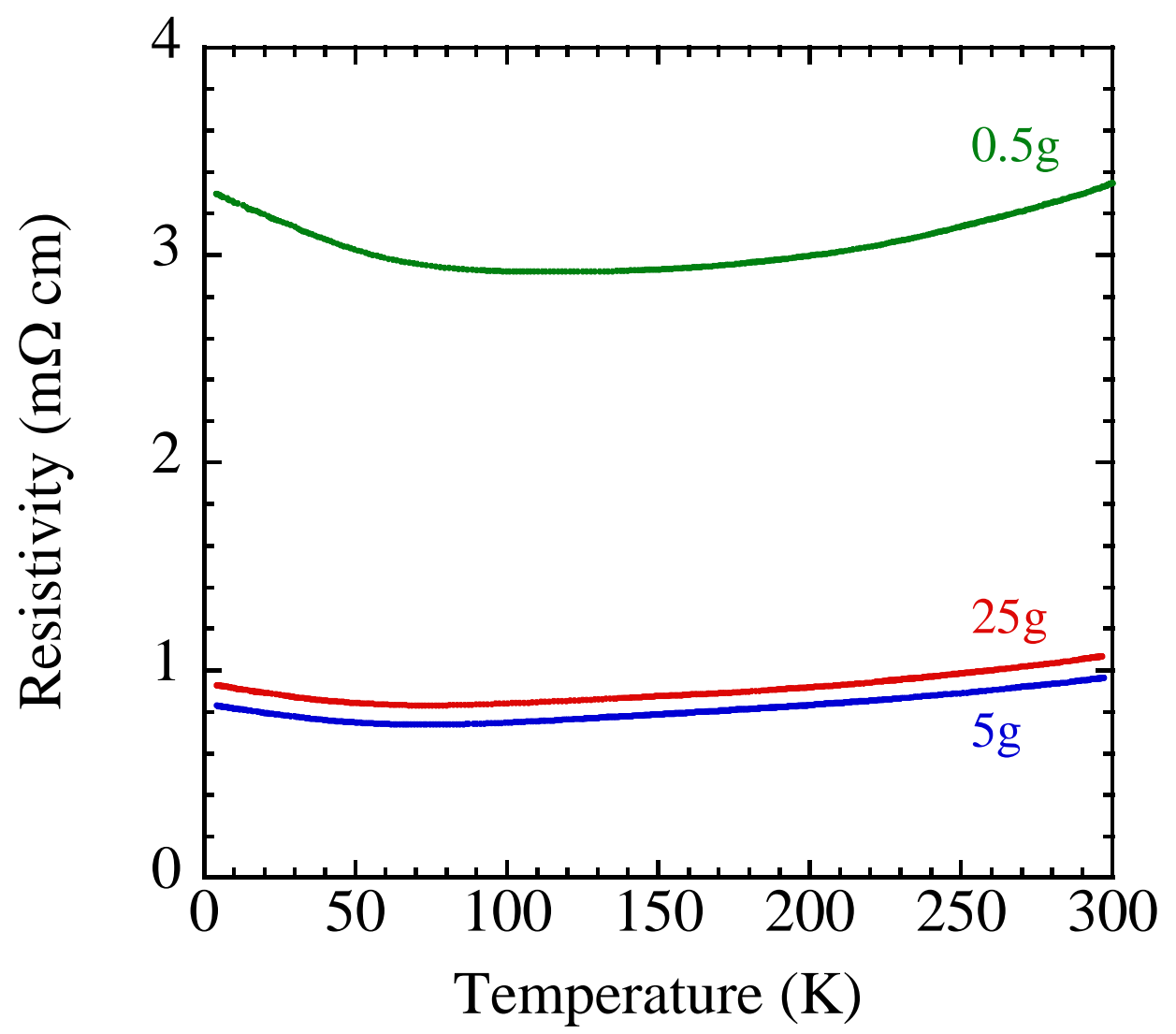


Fig. 4

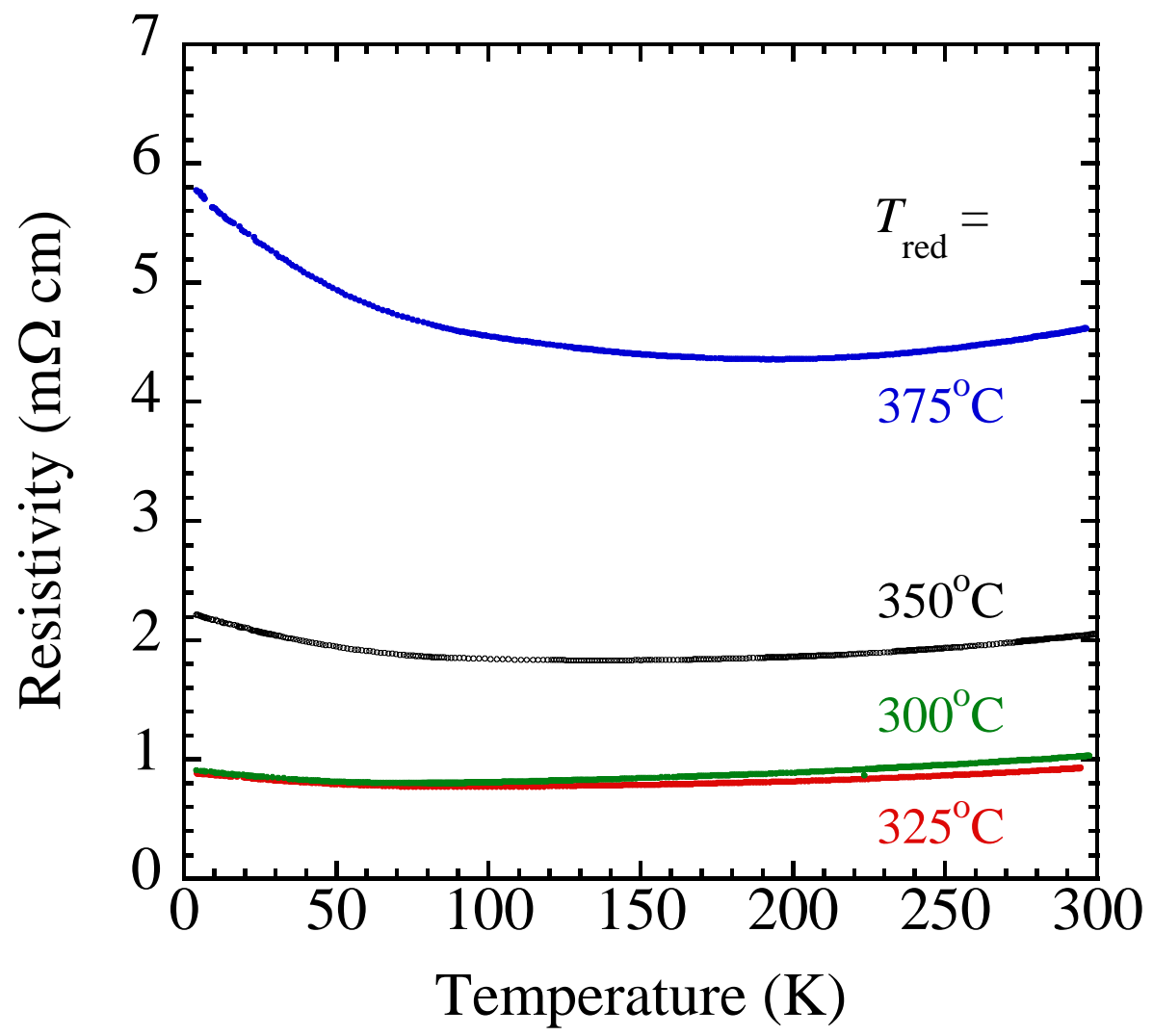


Fig. 5
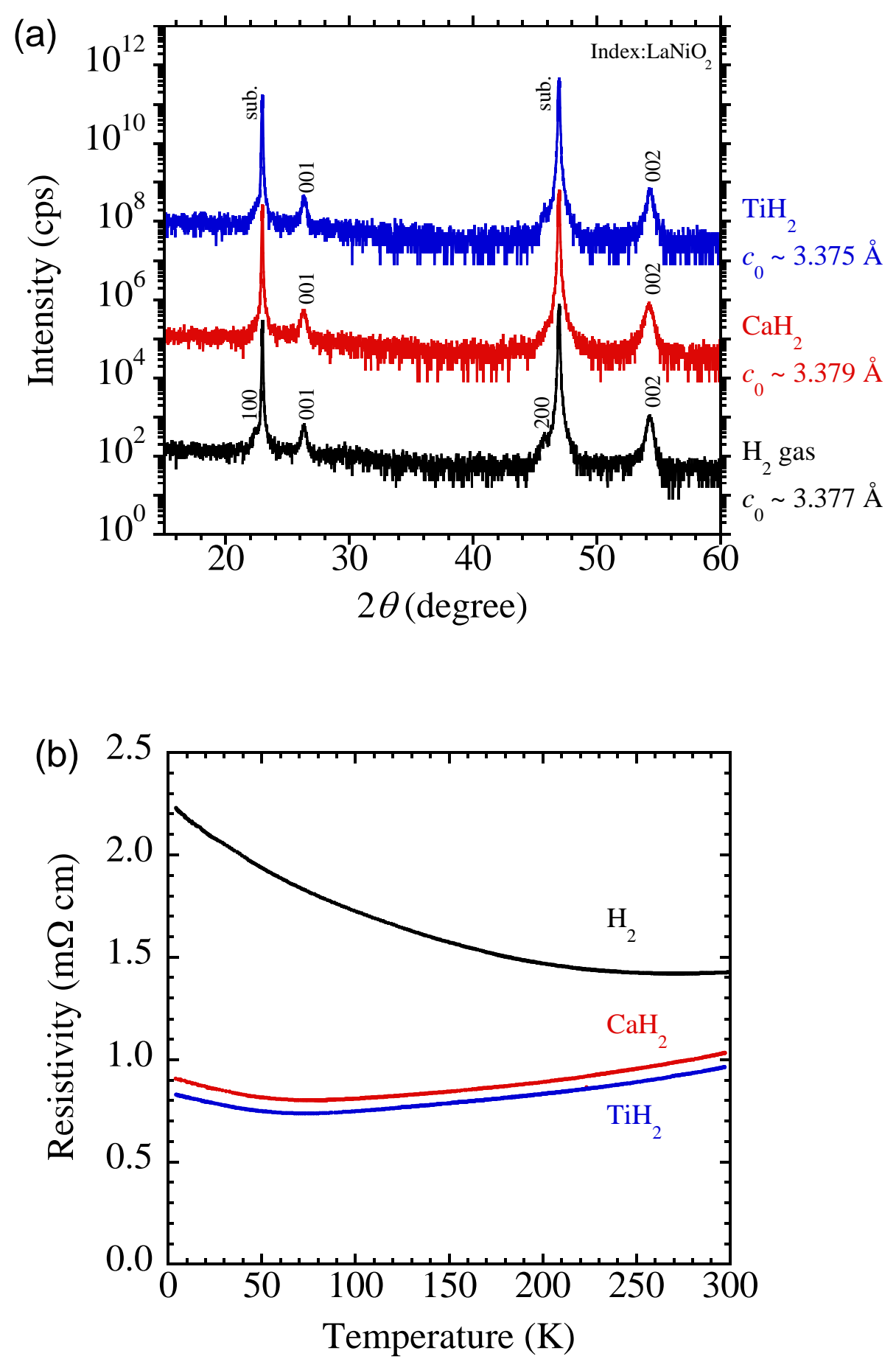